\title{
ELASTO-PLASTIC ANALYSIS WITH CONSTITUTIVE RELATION BASED ON FUZZY REASONING
}

\author{
Ikutaro KUMAZAKI ${ }^{1}$, Eiichi WATANABE ${ }^{2}$ and Hitoshi FURUTA ${ }^{3}$
}

\author{
${ }^{1}$ Member of JSCE, M. Eng., Research Engineer, Research and Development Center, Chubu Electric Power Co., \\ Inc. (Odaka-cho, Midori-ku, Nagoya 459 Japan) \\ ${ }^{2}$ Member of JSCE, Dr. Eng., Professor, Dept. of Civil Engineering, Kyoto University (Yoshida Honmachi, Sakyo- \\ ku, Kyoto 606-01 Japan) \\ ${ }^{3}$ Member of JSCE, Dr. Eng., Professor,Dept. of Informatics, Kansai University (Ryozenji-cho, Takatsuki City, \\ Osaka 569 Japan)
}

\begin{abstract}
A tuning method is formulated to express arbitrary curves with the fuzzy inference rules and the efficiency and the applicability of the method are demonstrated through several numerical calculations. A method to represent the arbitrary curves based on the fuzzy reasoning is applied to a modelling of hysteretic curves on simple plate elements under the repetitive compressive-tensile load. Using this method, so-called Fuzzy Constitutive Relation is applied to the prediction of the cyclic behavior concerned with a section of the thin-walled hollow segments under the constant compressive thrust and the repetitive bending.
\end{abstract}

Key Words : elastoplastic analysis, constitutive relation, hysteretic curve, fuzzy reasoning, learning, identification, double flange model, elastic web model, elastoplastic web model

\section{INTRODUCTION}

In order to grasp and predict the ultimate state of a structure/member, its nonlinear hysteretic behavior is important, which is found out of the constitutive relation of a material and the general load-displacement relation considering the local instability 1 ,2). Recently design methods proceed to the Limit State Design Method so that a method of modelling which is simplified and capable of precision is expected. So far, on various nonlinear behaviors, many experimental data and case studies using finite element analysis of structural member and element are accumulated. Consequently if an appropriate modelling method is developed with aid of the accumulation and is effectively applied to the numerical analysis, it is convenient toward solving the problems to improve the accuracy and the efficiency for the nonlinear analysis.

Of late, because of progress of the large computer, the finite element method etc. which are discretization methods are used in analyzing the strength of structures. Composite nonlinear analysis has been enabled taking account of the initial imperfections such as the initial deformation and the residual stress considering the geometrical and material nonlinearity. It is, however, quite timeconsuming and expensive to carry out an over-all structural analysis in which local instability is considered under the repetitive load even if an advanced technique is utilized. Therefore, the main purpose of this paper is to present a modelling of the hysteretic curves based on the fuzzy reasoning and to show the effectiveness of Fuzzy Constitutive Relation of thin steel plate elements, namely, flange plates, applying it to the prediction of the cyclic behavior concerned with a section of thinwalled hollow segments under the combined action of constant axial compressive force and repetitive bending.

In recent years, the fuzzy reasoning has been

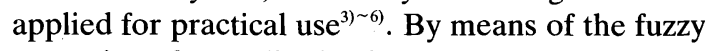
reasoning, the qualitative knowledge of a specialist can be represented as the fuzzy inference rules which are specified in the form of If $\cdots$ then $\sim$ rules. The characteristics of the system based on the fuzzy reasoning are as follows. The ability of recognition, judgment and consideration can be easily introduced so as to treat the complexity in the dynamic behavior and the imperfection of information due to the shortage of the data. The construction of the system is not difficult because rules can be easily established. Also, on account of plural rules with 
membership grades adopted as weights, smooth and precise control becomes possible. Furthermore, a model that entirely preserves the degree of accuracy can be constructed, and so forth. However if the fuzzy inference rules established by the specialist are applied as they are, they may not work in a desirable way. On such an occasion, it is necessary to do tuning in order to optimize the parameters of the antecedent and consequent parts composing each fuzzy inference rule. By way of the tuning method, a method which can automatically tune the consequent part of the inference rules has been developed with aid of the Hopfield Neural Network. According to the Hopfield Neural Network, the parameters are tuned so as to minimize the energy function corresponding to the evaluation function of the system. Namely, by treating the error between the control operation instructed by an operator and the result from the fuzzy reasoning as the energy function, the consequent part is tuned. This method has been applied to the identification of nonlinear problems by Nomura, Hayashi, Wakami ${ }^{7)}$. Besides, this Hopfield Neural Network has been applied to the control problem of the vibration of offshore structures subjected to the wave force by Minami, Watanabe, Furuta ${ }^{8)}$. In this Hopfield Neural Network model, however, a target of tuning is only the consequent part of the fuzzy inference rules, and the tuning of the antecedent part has not been considered and the antecedent part has made to be constant.

Meanwhile, in this study, a method which both the antecedent and consequent parts of the fuzzy inference rules are tuned simultaneously is adopted. In this method of tuning, the parameters of the antecedent part that determine the shape of the membership functions and the parameters of the consequent part are tuned automatically by means of the descent method using the inputoutput data acquired from an expert or an experiment. By Using the tuning method, it is possible to express an arbitrary curve through the fuzzy reasoning. The fuzzy reasoning enables us to give a good approximation curve, using a few inference rules. The applicability and the effectiveness of the curve approximation by the fuzzy reasoning has been verified through a lot of practical application of fuzzy control. By using the approximation method based on the fuzzy reasoning, hysteretic curves of a material can be represented in a simpler manner. Because hysteretic curves, in general, show complicated behaviors, it is not easy to predict the behavior exactly even if lots of complex functions are utilized ${ }^{14}$. Observing the variation of the parameters according to the loading cycles, some rules are derived for the determination of the parameters. The applicability and the efficiency of the Fuzzy Constitutive Model is demonstrated through the comparison between the experimental results and the results calculated.

\section{IDENTIFICATION METHOD OF FUZZY INFERENCE RULES ${ }^{\text {9) 15) }}$}

\section{( 1 ) Definition of Fuzzy Constitutive Relation}

The fuzzy inference rules are expressed in the form of If $\cdots$ then $\sim$, where the part, $\cdots$ of these rules is called antecedent part, and the part, is called consequent part.

It is assumed that the antecedent part of fuzzy inference rules used in this research has a variable, the number of membership functions is five and hence the number of the fuzzy inference rules is five. It may be said that a large number of membership functions result in being hard to deal with a model. On the other hand, if there are very few membership functions, the accuracy of approximation by the model will not be fine. That is why it is assumed that the number of membership functions is five.

If the input is expressed by $\varepsilon$, and the output is expressed by $\sigma$, the inference rules of the fuzzy reasoning can be expressed by the following expressions ;

$$
\begin{aligned}
& \text { Rule } 1: \text { If } \varepsilon \text { is } \tilde{A}_{1} \text { then } \sigma=f_{1} \\
& \text { Rule 2: If } \varepsilon \text { is } \tilde{A}_{2} \text { then } \sigma=f_{2} \\
& \text { Rule } 3: \text { If } \varepsilon \text { is } \tilde{A}_{3} \text { then } \sigma=f_{3} \\
& \text { Rule } 4: \text { If } \varepsilon \text { is } \tilde{A}_{4} \text { then } \sigma=f_{4} \\
& \text { Rule } 5: \text { If } \varepsilon \text { is } \tilde{A}_{5} \text { then } \sigma=f_{5} \\
& \text { Input } \varepsilon_{0} \\
& \text { output }
\end{aligned}
$$

where the symbol $\sim$ indicates fuzzy quantity and $f_{i}$ is a real number. It is noted that the consequent part is defined by crisp numbers. In this study, we call one set of these fuzzy inference rules "Fuzzy Constitutive Relation (FCR)", because the constitutive relation of a material is expressed by the input-output relation through the fuzzy inference rules as shown above.

\section{( 2 ) Fuzzy Reasoning}

Each membership function of the antecedent part is expressed by an isosceles triangle as shown in Fig.1. The parameters determining the shape of the triangle membership function are the central point value $a_{i}$ and the width $b_{i}$. The output of fuzzy reasoning $z_{0}$ can be derived from the following 


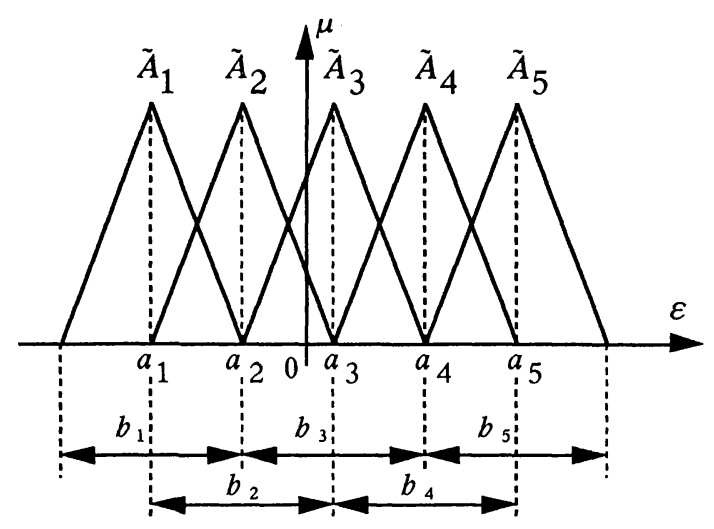

Fig.1 Membership functions

equations ;

$$
\begin{gathered}
\mu_{\tilde{A}_{i}}(\varepsilon)=1-\frac{2\left|\varepsilon-a_{i}\right|}{b_{i}}(i=1,2, \cdots, n) \\
h_{i}=\mu_{\tilde{A}_{i}}(\varepsilon) \\
z_{0}=\frac{\sum_{i=1}^{n} f_{i}(\varepsilon) h_{i}}{\sum_{i=1}^{n} h_{i}}
\end{gathered}
$$

where $h_{i}$ is the membership grade for the $i$-th membership function on the $\varepsilon$-axis for the value of $\varepsilon$.

\section{( 3 ) Learning of Consequent Part}

It is assumed that the learning of a real number of the consequent part is expressed by the following formula ;

$$
f_{i}^{\text {new }}=f_{i}^{\text {old }}+\alpha h_{i}\left(Z_{e}-z_{0}\right)
$$

where $\alpha$ is a learning coefficient which concerns the computation time and $Z_{e}$ is a desirable output and $z_{0}$ is the output by fuzzy reasoning. If the number of experimental data is insufficient, the desirable output is empirically supplied considering past research results. The meaning of Eq.(5) is that if the membership grade $h_{i}$ of a pair of the input data for the $i$-th fuzzy inference rule becomes large, $f_{i}^{\text {old }}$ is greatly changed multiplying $\left(Z_{e}-z_{0}\right)$ by $h_{i}$. Because $h_{i}$ is large, the real number of the consequent part of the $i$-th inference rule may greatly influence the change of the entire output $z_{0}$, that is to say, the value of the consequent part of the $i$-th inference rule can be greatly changed. On the other hand, if the membership grade $h_{i}$ is small, $f_{i}^{\text {old }}$ is hardly changed.

\section{(4) Learning of Antecedent Part}

The learning functions of the central value $a_{i}$ and the width $b_{i}$ of the membership function of the $i$-th rule is expressed by the following formulae;

$$
\begin{aligned}
& a_{i}^{\text {new }}=a_{i}^{\text {old }}-\beta \frac{\partial E}{\partial a_{i}}(\beta>0) \\
& b_{i}^{\text {new }}=b_{i}^{\text {old }}-\gamma \frac{\partial E}{\partial b_{i}}(\gamma>0)
\end{aligned}
$$

where $\beta$ and $\gamma$ are coefficients of learning which concern the computation time, and $E$ is an evaluation function which is defined in the following :

$$
E=\frac{1}{2}\left(Z_{e}-z_{0}\right)^{2}
$$

The values, $a_{i}$ and $b_{i}$ are determined so as to minimize the evaluation function $E$. From Eqs.(2) to (4) and (8), the gradients $\partial E / \partial a_{i}$ is expressed as shown below;

$$
\frac{\partial E}{\partial a_{i}}=\frac{\partial E}{\partial\left(Z_{e}-z_{0}\right)} \frac{\partial\left(Z_{e}-z_{0}\right)}{\partial z_{0}} \frac{\partial z_{0}}{\partial h_{i}} \frac{\partial h_{i}}{\partial \mu_{\tilde{A} i}} \frac{\partial \mu_{\tilde{A}_{i}}}{\partial a_{i}}
$$

where

$$
\begin{gathered}
\frac{\partial E}{\partial\left(Z_{e}-z_{0}\right)}=Z_{e}-z_{0} \\
\frac{\partial\left(Z_{e}-z_{0}\right)}{\partial z_{0}}=-1 \\
\frac{\partial z_{0}}{\partial h_{i}}=f_{i} \frac{1}{\sum_{i=1}^{n} h_{i}}+\left(\sum_{i=1}^{n} f_{i} h_{i}\right)(-1) \frac{1}{\left(\sum_{i=1}^{n} h_{i}\right)^{2}} \\
=f_{i} \frac{1}{\sum_{i=1}^{n} h_{i}}-\frac{\sum_{i=1}^{n} f_{i} h_{i}}{\sum_{i=1}^{n} h_{i}} \frac{1}{\sum_{i=1}^{n} h_{i}} \\
=\left(f_{i}-z_{0}\right) \frac{1}{\sum_{i=1}^{n} h_{i}} \\
\frac{\partial h_{i}}{\partial \mu_{\tilde{A}}}=1 \\
\frac{\partial \mu_{\tilde{A}_{i}}}{\partial a_{i}}=\frac{2 \operatorname{sgn}\left(\varepsilon-a_{i}\right)}{b_{i}}
\end{gathered}
$$

Therefore, by substituting Eqs.(10) to (14) into Eq.(9), it turns out that the gradient $\partial E / \partial a_{i}$ is expressed as

$$
\frac{\partial E}{\partial a_{i}}=-\frac{2 \operatorname{sgn}\left(\varepsilon-a_{i}\right)\left(Z_{e}-z_{0}\right)\left(f_{i}-z_{0}\right)}{b_{i} \sum_{i=1}^{n} h_{i}}
$$

Similarly,

$$
\frac{\partial E}{\partial b_{i}}=\frac{\partial E}{\partial\left(Z_{e}-z_{0}\right)} \frac{\partial\left(Z_{e}-z_{0}\right)}{\partial z_{0}} \frac{\partial z_{0}}{\partial h_{i}} \frac{\partial h_{i}}{\partial \mu_{\tilde{A}_{i}}} \frac{\partial \mu_{\tilde{A}_{i}}}{\partial b_{i}}
$$

where

$$
\frac{\partial \mu_{\tilde{A} i}}{\partial b_{i}}=\frac{2\left|\varepsilon-\alpha_{i}\right|}{b_{i}^{2}}
$$

By substituting Eqs.(10) to (13) and (17) into Eq.(16), the gradient $\partial E / \partial b_{i}$ turns out to be 


$$
\frac{\partial E}{\partial b_{i}}=-\frac{2\left(Z_{e}-z_{0}\right)\left(f_{i}-z_{0}\right)\left|\varepsilon-a_{i}\right|}{b_{i}^{2} \sum_{i=1}^{n} h_{i}}
$$

Therefore, the formulae of the learning rule of the antecedent part are derived by substituting Eqs.(15) and (18) into Eqs.(6) and (7), respectively.

$$
\begin{gathered}
a_{i}^{\text {new }}=a_{i}^{\text {old }}+2 \beta \frac{\operatorname{sgn}\left(\varepsilon-a_{i}\right)\left(Z_{e}-z_{0}\right)\left(f_{i}-z_{0}\right)}{b_{i} \sum_{i=1}^{n} h_{i}} \\
b_{i}^{\text {new }}=b_{i}^{\text {old }}+2 \gamma \frac{\left(Z_{e}-z_{0}\right)\left(f_{i}-z_{0}\right)\left|\varepsilon-a_{i}\right|}{b_{i}^{2} \sum_{i=1}^{n} h_{i}}
\end{gathered}
$$

\section{( 5 ) Identification Algorithm of Fuzzy Infer- ence Rules}

The algorithm of identifying the fuzzy inference rules is as follows.

(1) The initial setting of the parameters of the antecedent and consequent parts of the fuzzy inference rules is conducted.

(2) A pair of desirable data $\left(\varepsilon_{0}, Z_{e}\right)$ is input. (3) The degree for each membership function $h_{i}$ is calculated by Eq.(2).

(4) The result by the fuzzy reasoning $z_{0}$ is calculated by Eq.(4).

(5) The parameters of the consequent part $f_{i}$ are renewed by Eq.(5) with the values of $Z_{e}, z_{0}$, and $h_{i}$ used.

(6) Again, the output by the fuzzy reasoning $z_{0}$ is calculated by Eq.(4) with the new values of the consequent part $f_{i}$ used.

(7) The parameters of the antecedent part of the fuzzy inference rules $a_{i}$ and $b_{i}$ are renewed by Eqs.(19) and (20), using the new values of the consequent part $f_{i}$, the result of the fuzzy reasoning $z_{0}$, and the values of $h_{i}$, and $Z_{e}$.

( 8 ) If the expression, $\delta=\left|Z_{e}-z_{0}\right|<c$, holds $m$ times consecutively, where $c$ being a real value and $m$ being a natural number are used as criteria, go to step (9), otherwise go to step (2).

(9) The identification of the parameters of the antecedent and consequent parts is completed.

\section{REPRESENTATION OF ARBIT- RARY CURVES BY FUZZY INFER- ENCE RULES ${ }^{16,17)}$}

\section{(1) Expression of Arbitrary Curves by Fuzzy Inference Rules}

If $k$ set of input values $\varepsilon_{j}$ are given for the identified fuzzy inference rules, the fuzzy reasoning is conducted for each of the inputs, to derive $k$ set of the output values $z_{j}$. It is noted that $k$ is an arbitrary natural number. The constitutive relation of a material can be expressed by depicting the data
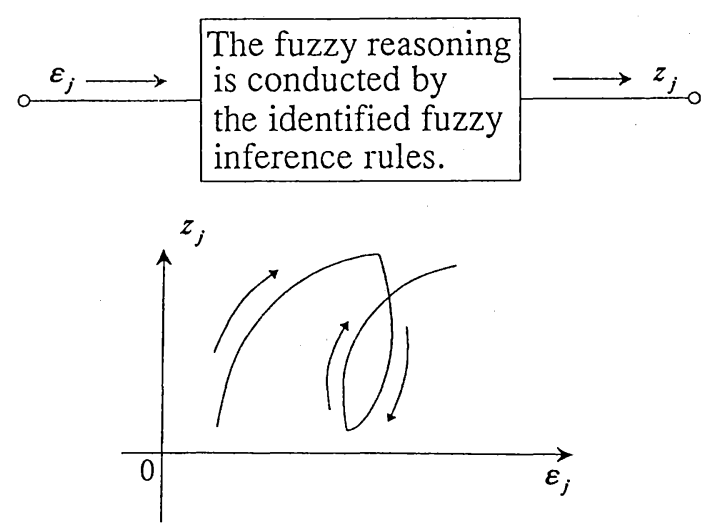

Fig.2 Expression of curve by rules

$\left(\varepsilon_{j}, z_{j}\right)(j=1,2, \cdots, k)$ which are obtained like this.

\section{( 2 ) Demonstration of Identification of Fuzzy Inference Rules}

In order to demonstrate the validity of the present method of identifying the fuzzy inference rules, we presented some numerical examples.

Figs. 4 to 6 show the hysteretic curves plotted using the stress-strain data obtained from an experiment of a specimen under the repetitive compressive-tensile loading and the curves represented by the fuzzy inference rules identified by use of the experimental data as the learning data.

The specimen used to get the experimental data is Specimen A (SA type) shown in Fig.3. It is noted that the compressive side is regarded as that of positiveness and the tensile side is considered as that of negativeness.

In each case of Fig.4, Fig.5 and Fig.6, the number of the experimental data is 396,4586 and 12030 respectively. Incidentally, in these instances, the input-output relation data obtained from the experiment are regarded as the desirable data for the examples. Furthermore, in the identification of the fuzzy inference rules, let each coefficient of $\alpha$, $\beta$ and $\gamma$, which concern the computation time, be 0.0001 . The coefficients $\alpha, \beta, \gamma$ concern the computation time. If the coefficients are too small, the computation time becomes very large. On the other hand, if the coefficients are too large, the values of $f_{i}, a_{i}, b_{i}$ in Eqs. (5) to (7) move to and fro, hence does not converge. From this point of view, the values of $\alpha, \beta, \gamma$ are decided through trial and error.

The parameters of the antecedent and consequent parts of the fuzzy inference rules are identified, using the algorithm that was described in the previous chapter.

As a measure of the degree of the agreement, we 

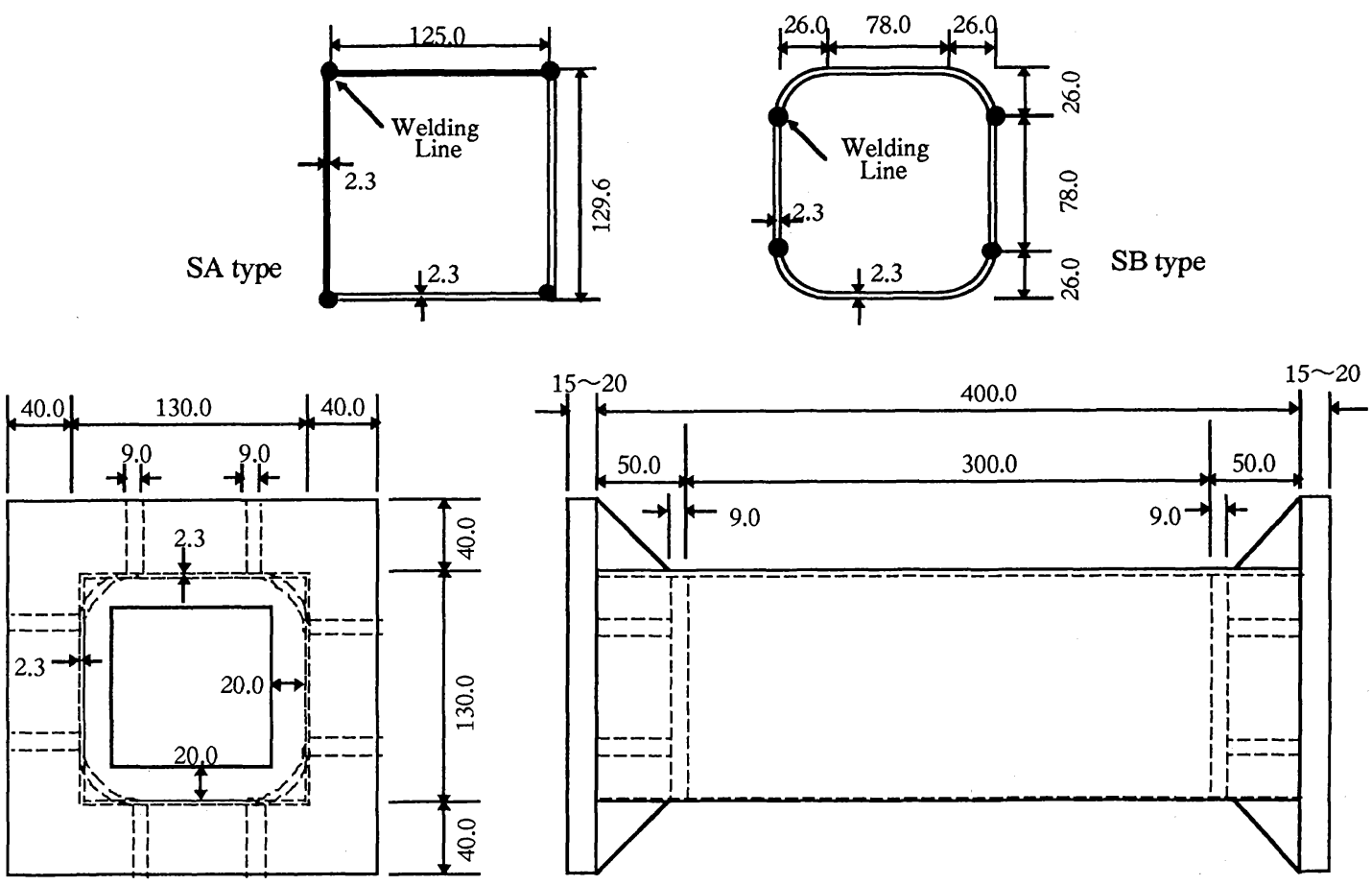

Fig.3 Specimens used for compressive-tensile test

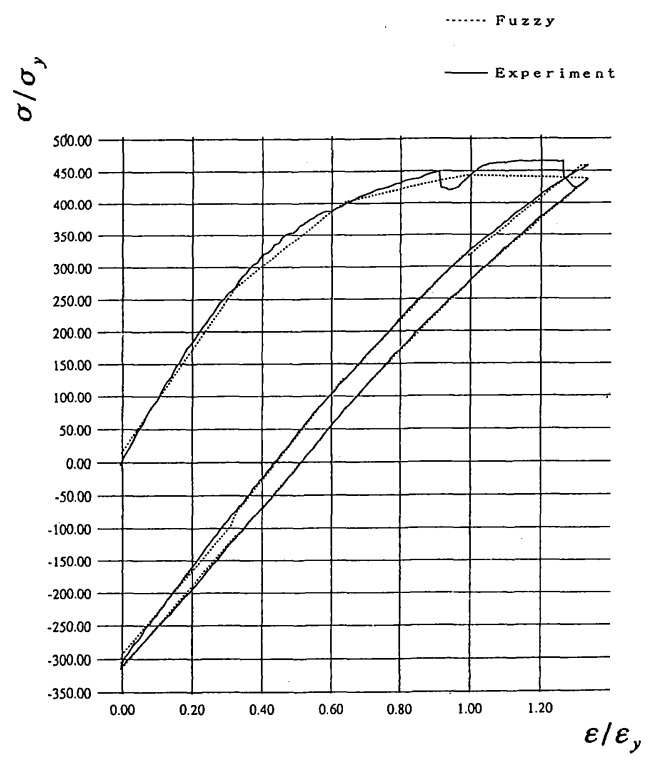

Fig.4 Learning of experimental data

use the following expression.

$$
s^{2}=\frac{1}{n} \sum_{j=1}^{n}\left(z_{0}-Z_{e}\right)_{j}^{2}
$$

In the cases of Figs. 4 to 6 , the values of $s^{2}$ are , $5.995 \times 10^{-5}, 9.555 \times 10^{-4}$ and $1.102 \times 10^{-2}$ respectively. It could be said that the prominent nonlinear

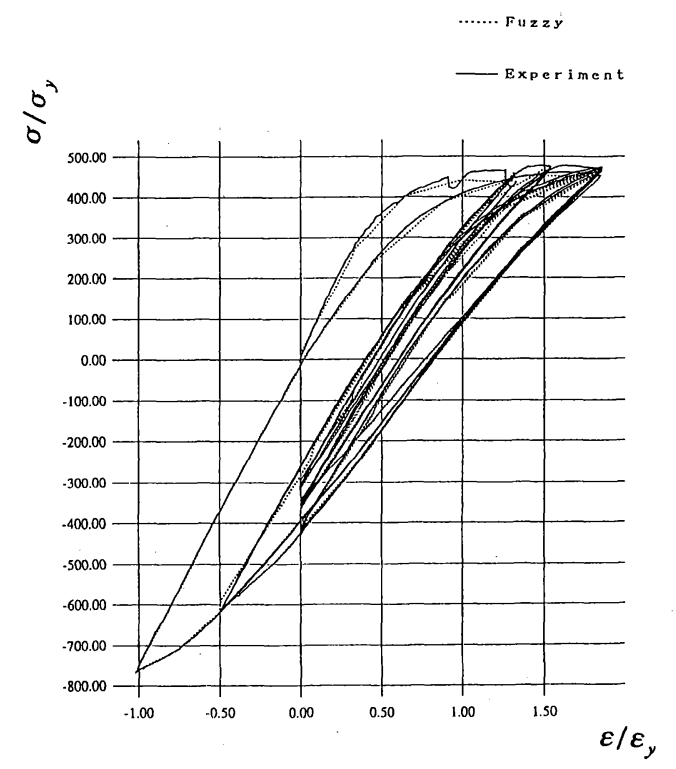

Fig.5 Learning of experimental data

domain in which the large axial strain occurs has a relatively large error, but the degree of the agreement is well overall. 


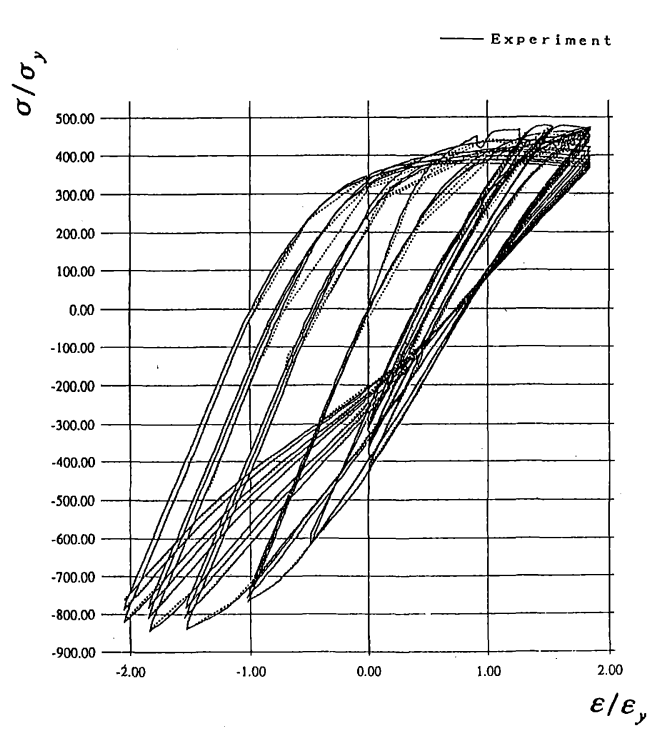

Fig.6 Learning of experimental data

Table 1 Design measurements of specimens SA and SB

\begin{tabular}{|c|c|c|c|c|c|}
\hline SPECIMEN & $\begin{array}{c}\text { PLATE } \\
\mathbf{B}(\mathrm{mm})\end{array}$ & $\begin{array}{c}\text { CORNER } \\
\mathrm{r}(\mathrm{mm})\end{array}$ & $\begin{array}{c}\text { THICKNESS } \\
t(\mathrm{~mm})\end{array}$ & $\begin{array}{c}\text { LENGTH } \\
\mathrm{L}(\mathrm{mm})\end{array}$ & $\begin{array}{c}\text { AREA } \\
\mathrm{B} \times \mathrm{t}(\mathrm{m} \mathrm{m})\end{array}$ \\
\hline SA-Type & 130.0 & - & 2.3 & 300.0 & 11.73 \\
\hline SB-Type & 78.0 & 26.0 & 2.3 & 300.0 & 10.77 \\
\hline
\end{tabular}

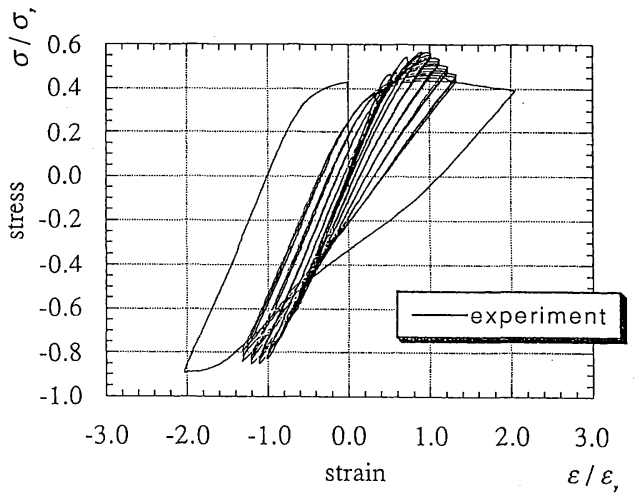

Fig.7 Stress-strain curve of SA type

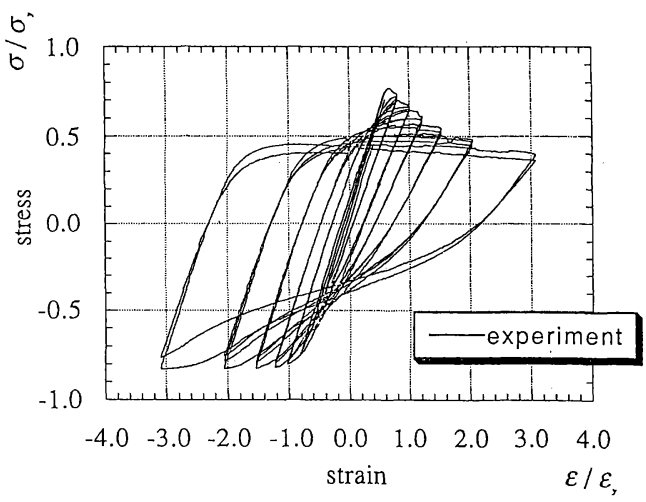

Fig.8 Stress-strain curve of SB type

Table 2 Actual measurements of specimens SA and SB

\begin{tabular}{|c|c|c|c|c|c|c|c|c|}
\hline \multirow{2}{*}{ SPECIMEN } & \multicolumn{2}{|c|}{ PLATE 1 } & \multicolumn{2}{c|}{ PLATE 2 } & \multicolumn{2}{c|}{ PLATE 3 } & \multicolumn{2}{c|}{ PLATE 4 } \\
\cline { 2 - 8 } & $\mathrm{B} 1(\mathrm{~mm})$ & $\mathrm{t} 1(\mathrm{~mm})$ & $\mathrm{B} 2(\mathrm{~mm})$ & $\mathrm{t} 2(\mathrm{~mm})$ & $\mathrm{B} 3(\mathrm{~mm})$ & $\mathrm{t} 3(\mathrm{~mm})$ & $\mathrm{B} 4(\mathrm{~mm})$ & $\mathrm{t} 4(\mathrm{~mm})$ \\
\hline SA-Type & 129.8 & 2.219 & 129.9 & 2.339 & 129.9 & 2.345 & 129.8 & 2.386 \\
\hline SB-Type & 78.2 & 2.321 & 75.8 & 2.247 & 77.0 & 2.402 & 75.2 & 2.256 \\
\hline
\end{tabular}

\section{MODELLING OF FUZZY CON- STITUTIVE RELATION OF SIMPLE PLATE ELEMENT}

\section{(1) Variation of Rule Parameters with Adv- ance of Loading Cycle}

Axial stress-strain curves obtained by a compressive-tensile experiment on two types of specimens are shown in Figs.7 and 8. The steel type of the specimens is SS 41. It is noted that the compressive side is regarded as that of positiveness and the tensile side is considered as that of negativeness. Incidentally, an average of four values measured at four corners of the specimen is an axial displacement. And the axial stress and strain are nominal values. Besides, measurements of the specimens adopted for this compressivetensile experiment are tabulated in Table 1.

As can be seen from Tables 2 and 3, the specimens SA and SB used for obtaining the learning data have unusually large generalized width-thickness ratios. In practice, these kinds of plates are not used as the segments subjected to the cyclic loading. However, in this study a principal object is to develop a simplified modelling method to estimate the bending moment-curvature rela- 
Table 3 Actual measurements and yield points

\begin{tabular}{|l|c|c|c|c|}
\hline SPECIMEN & $\begin{array}{c}\text { CORNER } \\
\mathrm{r}(\mathrm{mm})\end{array}$ & $\begin{array}{c}\text { LENGTH } \\
\mathrm{L}(\mathrm{mm})\end{array}$ & $\begin{array}{c}\text { AREA } \\
\mathrm{B} \times \mathrm{t}(\mathrm{cm})\end{array}$ & $\begin{array}{c}\text { P y } \\
(\text { tonf })\end{array}$ \\
\hline SA-Type & - & 299.7 & 12.06 & 41.91 \\
\hline SB-Type & 26.62 & 299.2 & 10.75 & 37.37 \\
\hline
\end{tabular}

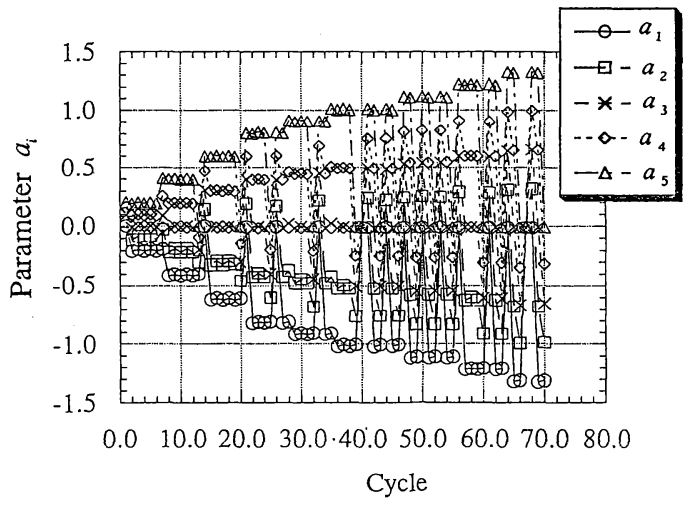

Fig.9 Variation of antecedent parameters $a_{i}$ (SA)

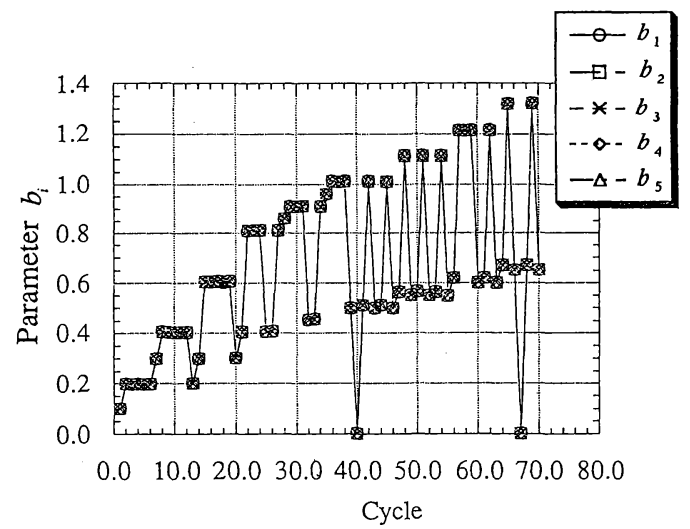

Fig.10 Variation of antecedent parameters $b_{i}$ (SA)

tion. It is not a primary object to investigate the dynamic characteristics as the earthquake-resistant segments of the plate elements. Hence, if the principal object is to develop the simplified modelling method to estimate the bending moment-curvature relation under the repetitive load, it may be said that using data related to these specimens has a significance.

The experimental data are utilized as the learning data for the identification of the antecedent and consequent parameters of the fuzzy inference rules. Figs.9 to 11 and Figs.12 to 14 show the vicissitudes of the parameters of the fuzzy inference rules, according to the advance of loading cycle. The parameters whose transitions are

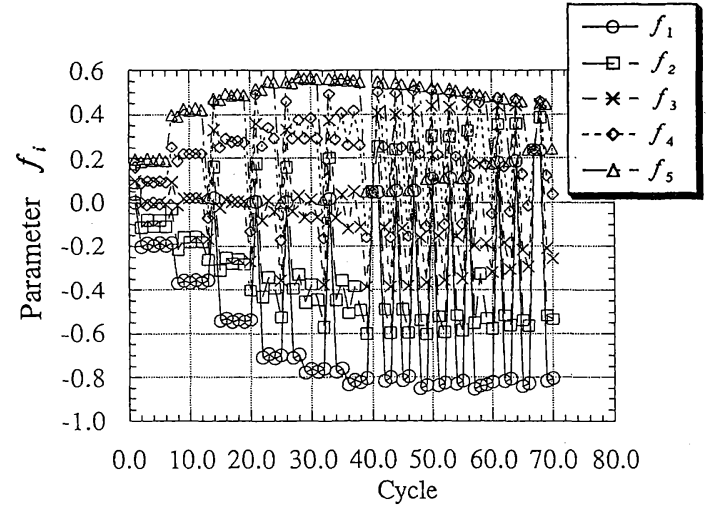

Fig.11 Variation of consequent parameters $f_{i}$ (SA)

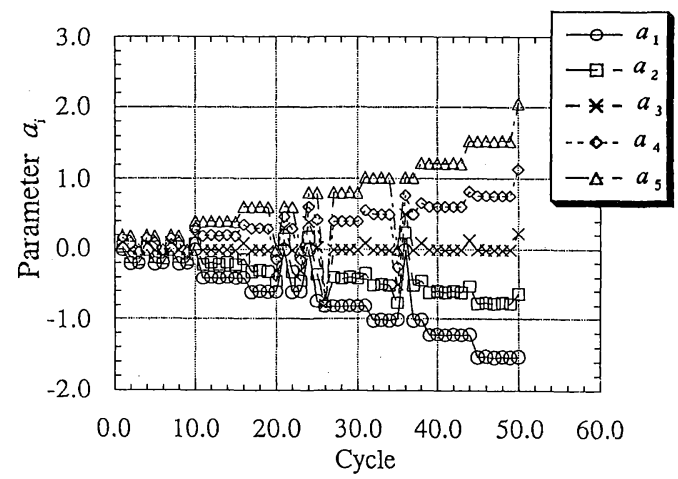

Fig.12 Variation of antecedent parameters $a_{i}(\mathrm{SB})$

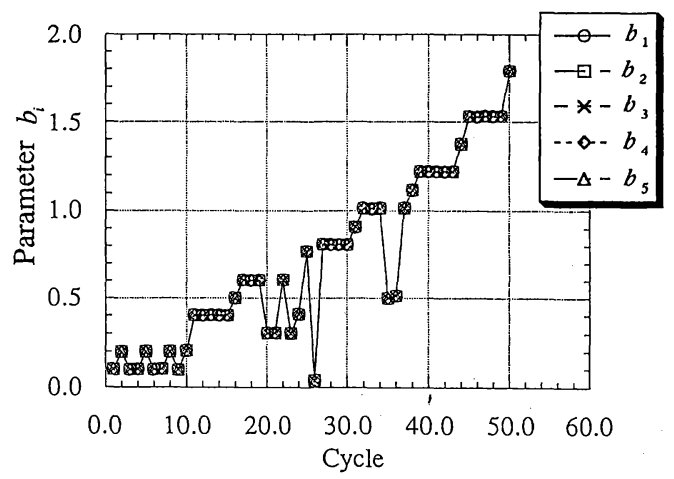

Fig.13 Variation of antecedent parameters $b_{i}(\mathrm{SB})$

depicted in Figs.11 to 13 and Figs.14 to 16 are identified with the experimental data as the learning data. Hereafter, examination and consideration are made by taking notice of the qualitative vicissitudes of each parameter accompanied with progress of the repetitive loading.

Two kinds of compressive-tensile experimental data are used as the learning data for the identification of the parameters. One has been 


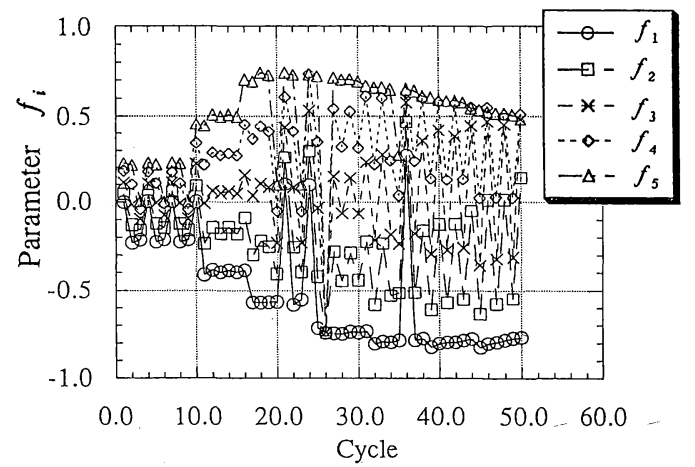

Fig.14 Variation of consequent parameters $f_{i}$ (SB)

obtained by testing the square sectional specimen and the other has been obtained by testing the round-cornered box type specimen. Hereafter, let the square sectional specimen be called Specimen A (SA type) and the round-cornered box type specimen be called Specimen B (SB type). The specimens, SA and SB, are shown in Fig.3. Figs.9 to 11 show the variation in the case that the parameters are identified making use of SA data as the learning data. And Figs.12 to 14 indicate the vicissitudes in the case that the parameters are identified by use of SB data. Still more, in Figs.9 and 12 , the vicissitudes of the antecedent parameters $a_{1} \sim a_{5}$ are shown, and the transitions of the antecedent parameters $b_{1} \sim b_{5}$ are depicted in Figs.10 and 13. Also, the changes of the consequent parameters $f_{1} \sim f_{5}$ are graphed out in Figs.11 and 14. Incidentally, the parameters $a_{1} \sim a_{5}$ are the central values of the triangles shaped by the membership functions and the lateral axis. The parameters $b_{1} \sim b_{5}$ are the width of the triangles. The parameters $f_{1} \sim f_{5}$ are the real numbers of the consequent part in the fuzzy inference rules.

\section{( 2 ) Consideration on Parameters of Fuzzy Constitutive Relation}

The change of the parameters $a_{1} \sim a_{5}$ and $b_{1} \sim b_{5}$ depends on the loading pattern in the experiment, hence qualitative physical significance does not turn up in the vicissitudes of $a_{1} \sim a_{5}$ and $b_{1} \sim b_{5}$. However, it is considered that the transitions of the consequent parameters $f_{1} \sim f_{5}$ are concerned with the qualitative physical characteristics on the dynamic behavior of the specimens subjected to repetitive compressive-tensile force.

There are two unique points in Figs.10 and 13. The parameter $b_{i}$ in Figs.10 and 13 is the width of the membership functions. The unique points appear in the parts where the stress-strain curves does not smoothly change. In that parts, the fuzzy reasoning is carried out within the very small strain interval. Accordingly, the two unique points appear.

The value of $f_{1}$ is guessed to represent the neighboring point from the leftmost dot of the half of each hysteretic loop because $f_{1}$ is the consequent part of the membership function which takes its position on the left-hand in the five membership functions. Accordingly, the change of the values of $f_{1}$ can be concluded to manifest the qualitative variation of turning points on the tensile side.

In the mean time, the value of $f_{5}$ is conjectured to express the nearby point from the most right dot of the half of each hysteretic loop since $f_{5}$ is the consequent part of the membership function that takes its position on the most right in the five membership functions. Hence, the transition of the value of $f_{5}$ can be surmised to represent the qualitative change of the turning points on the compressive side. Namely, $f_{1}$ is concerned with the qualitative vicissitudes of the strength to bear the load on the tensile side, while $f_{5}$ implies the qualitative transition of the strength to endure the load on the compressive side. In both Figs.11 and 14, $f_{1}$ reaches its peak earlier than $f_{5}$. This implies that the strength to bear the load increases stably on both the compressive and tensile side when subjected to the repetitive load and the strain amplitude is small at the first stage. However, local buckling occurs as the deformation out of the place develops when subjected to the compressive thrust and the repetitive number of loading becomes large, and the strain amplitude is made greater.

For that reason, if the buckling did not occur, the strength to endure the load would show the similar or same change on both the compressive and the tensile side. Accordingly, the two peaks of the $f_{1}$ and $f_{5}$ would take place at the almost symmetrical points. The shape of the curves of $f_{1}$ and $f_{5}$ would be symmetrical. Furthermore, in Figs.11 and 14, making comparison on $f_{5}$, the peak of the consequent parameter $f_{5}$ of the rule identified with the experimental data of SA type with the square section is lower, and also the degree of reduction of the value of $f_{5}$ is smaller as the loading cycle progresses. Meanwhile, the peak of $f_{5}$ of the identified rule with the experimental data of SB type with the round-cornered box type section is higher and the degree of decline of the value of $f_{5}$ is larger as the loading cycle advances. It is conjectured that this implies that in the case of SA type, the largest strength on the compressive side is smaller and also the degree of reduction of the strength is smaller as the loading cycle increase. In the meantime, in the case of SB type, the largest strength is larger and the degree of decline of the strength is larger going with advance of the cycle. 
Besides, as for the transition of $f_{1}$, its absolute value gradually becomes larger in proportion to the increase of the cycle in the same way as that of $f_{5}$. And the value of $f_{5}$ attains the peak point earlier than that of $f_{1}$ and continuously reduces after that point, whereas the absolute value of $f_{1}$ becomes larger without interruption after the value of $f_{5}$ has reached the peak point, and in the course of time, gains the peak point and then ends in getting smaller even if it is little by little.

It is surmised that although the strength on both the compressive and tensile sides grows on with progress of the cycle, on the compressive side the peak of the strength is attained earlier than that on the tensile side. Afterwards, the strength on the compressive side goes on reducing under the influence of the deformation out of the plane and the local instability, whereas on the tensile side the strength becomes larger successively after the peak of the strength has been attained on the compressive side and in due time, the collapse comes into existence.

\section{( 3 ) Empirical Determination of Fuzzy Con- stitutive Relation of Simple Plate Ele- ment}

The empirical determination of the constitutive relation of simple plate element is conducted based on the fuzzy reasoning. A Fuzzy Constitutive Relation is established, building up its argument on the basis of the consideration and observation of the vicissitudes of the identified rule parameters. The transition of the antecedent and consequent parameters of the five fuzzy inference rules is collectively assumed, using simple linear lines.

$a_{1} \sim a_{4}$ and $b_{1} \sim b_{5}$ are established automatically by setting one linear line which corresponds to the transition of $a_{5} . a_{5}$ is first determined among $a_{1} \sim a_{5}$, and then $a_{1}$ is established symmetrically as $a_{5}$, and then $a_{2} \sim a_{4}$ are determined so that they may divide the space between $a_{1}$ and $a_{5}$ into quarters. At this time, $a_{1} \sim a_{5}$ are determined so that they can cover the loading strain level. Accordingly, an important matter is how to establish $a_{5}$. How to decide the slope of $a_{5}$ is carried out in such a way that $a_{5}$ becomes the marginal slope to cover the strain level of the subjected cyclic loading.

As for $f_{i}$, curves by the fuzzy inference rules are represented in the context among $a_{i}, b_{i}, f_{i}$. First, a limitation of a curve to be able to express with $a_{i}$ and $b_{i}$ in the present cyclic loading point is found. Then, the lines of $f_{i}$ are established from the relation with the limitation.

Consequently, the transition of the antecedent parameters $a_{1} \sim a_{5}$ is set up by the linear lines as

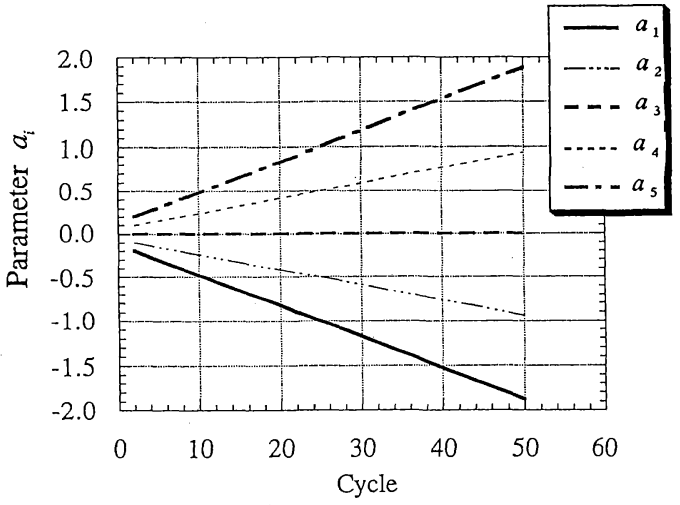

Fig.15 Assumed lines for antecedent parameters $a_{i}$

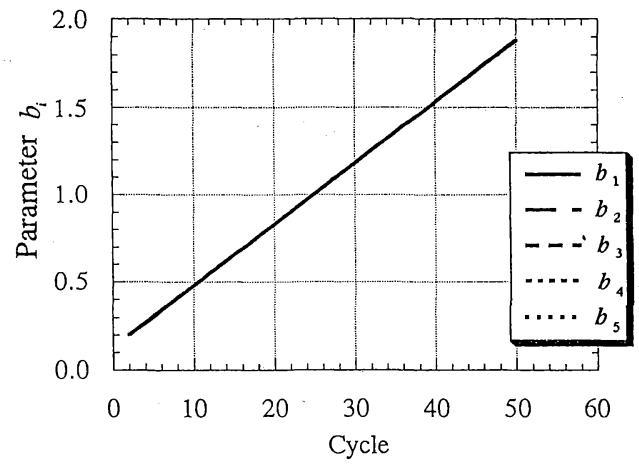

Fig.16 Assumed lines for antecedent parameters $b_{i}$

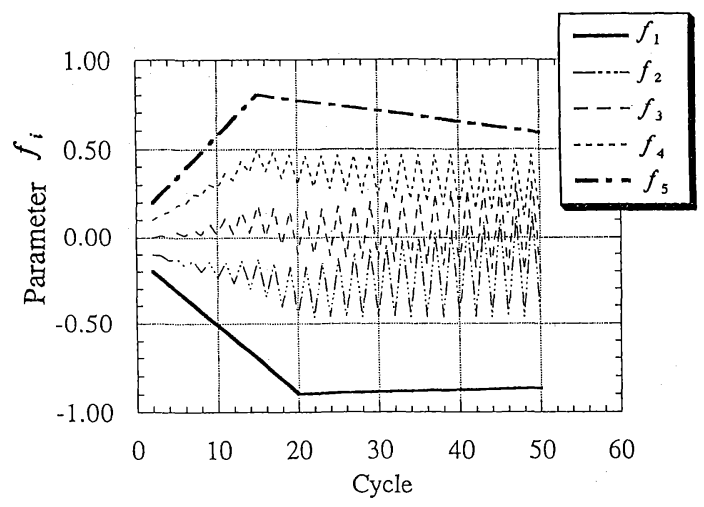

Fig.17 Assumed lines for consequent parameters $f_{i}$

shown in Fig.15. For the antecedent parameters $b_{1} \sim b_{5}$, they are established as shown in Fig.16. Fig.17 depicts the vicissitudes of the consequent parameters $f_{1} \sim f_{5}$. Incidentally, the transitions of the antecedent and consequent parameters of the fuzzy inference rules are established considering both $\mathrm{SA}$ and $\mathrm{SB}$.

As for $f_{1} \sim f_{5}, f_{1}$ influences how the strength on the tensile side changes, and $f_{5}$ influences how the 


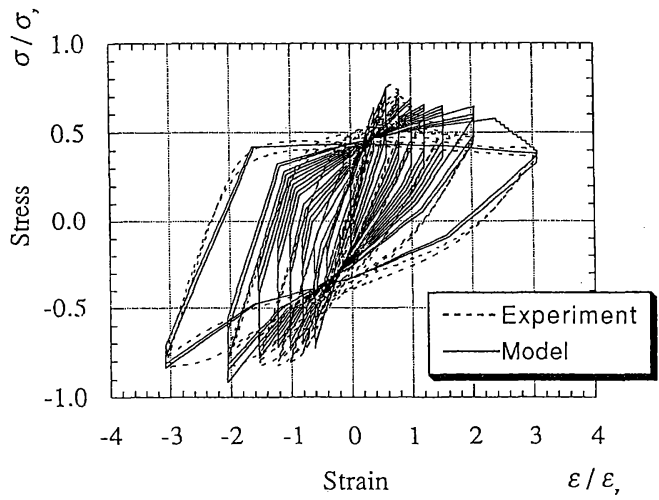

Fig.18 Fuzzy constitutive rclation of thin plate

strength on the compressive side changes. Because the most significant parameters $f_{1}$ and $f_{5}$ respectively undergo similar changes qualitatively as turning out from the observation of Figs.11 and 14, the linear lines corresponding to the vicissitudes of $f_{1}$ and $f_{5}$ can be derived as shown in Fig.17. As for the peak values of $f_{1}$ and $f_{5}$, the peak value of $f_{1}$ identified by use of the experimental result of SA is -0.85 , and the peak value of $f_{1}$ identified making use of the experimental result of SB is -0.78 . Meanwhile, the peak value of $f_{5}$ identified by SA is 0.55 , and the peak value of $f_{5}$ identified by SB is 0.73 . On the analogy of these results, the peak values of $f_{1}$ and $f_{5}$ are obtained.

\section{(4) Comparison between Fuzzy Constitutive Relation and Experimental Data of Sim- ple Plate Element}

The computer program is made to express the stress-strain curve based on fuzzy reasoning, and the validity of the modelling is examined, comparing with the experimental results. It is necessary to input the peak points of the parameters $f_{1}$ and $f_{5}$ so as to obtain the stress-strain hysteretic curves under the repetitive compressive-tensile load. In the examination of the modelling, the peak of $f_{1}$ is put -0.815 , and the peak of $f_{5}$ is put 0.64 with useful information furnished from the transitions of $f_{1}$ and $f_{5}$.

A comparison between the stress-strain relation by the model and the experimental result is shown in Fig.18. As can be seen from Fig.18, the limit points in the compression area can not be estimated very well. One reason may lie in the number of the fuzzy inference rules as five, which possibly influences the estimated precision. This time, the simple linear lines related to the rule parameters are assumed, but if nonlinear curves are assumed, the degree of the precision probably becomes finer.

From the obtained results, it may be mentioned that the stress-strain hysteretic behavior under the cyclic compressive-tensile load is expressed in certain degree of success by the fuzzy constitutive relation. Nevertheless, there is a milling at one part in the graph expressed by the fuzzy constitutive relation. The milling occurs in a domain which the strain amplitude is the largest in the graph. It is considered that because the number of the membership functions used for the fuzzy inference rules is rather few (i.e., five), the milling occurs. Hence, if the number of the membership functions is more than five, the hysteretic curve will be expressed smoother without the milling.

According to the experimental results, the peak points shift remarkably after the specimens have been subjected to the considerably great tensile strain. But it is not evident whether the great tensile strain causes the remarkable shift of the peak points. Some experiments are expected so as to verify the problem.

In the repetitive bending tests, it is hardly possible that the plate element comes up to collapse on the tensile side. Therefore, the behavior in the domain of great strain amplitude can be concluded to scarcely influence the analysis of this research work. For that reason, the number of the membership functions is remained five even if the graph expressed by the fuzzy inference rules has partly the milling in the domain where the strain amplitude is the largest.

\section{APPLICATION OF FUZZY CON- STITUTIVE RELATION TO ANALY- TICAL MODELLING ${ }^{18) \sim 24)}$}

\section{(1) Outline}

In this chapter, the fuzzy constitutive relation of simple plate element is applied to three types of analytical models so as to evaluate the cyclic behavior concerned with a section of thin-walled hollow segments under the constant axial compressive thrust and the repetitive bending combined.

The segments with box type section are adopted as the thin-walled hollow segments in this analysis. The analysis is done in such a way that the strains of flange and web plates must satisfy dynamic condition, that is, the increment of the axial force is zero when the increment of curvature is given, and the general restorative characteristics on the composite members is evaluated. At this time, the fuzzy constitutive relation described in the former chapter is utilized as the stress-strain relations on the thin plates with upper and lower flanges. Incidentally, the compressive side is regarded as that of positiveness and the tensile side is 


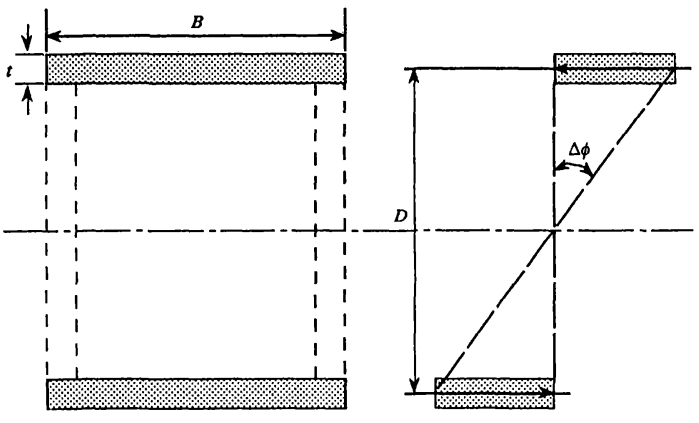

Fig.19 Double flange model

considered as that of negativeness in this analysis.

\section{( 2 ) Double Flange Model}

As the first model, Double Flange Model is adopted. The model is shown in Fig.19 This model is often used for the analysis on the buckling strength of steel structural members. It is assumed that the web elements are fictitious elements which do not have an area and they are attached for only one purpose that they sustain the shape of the beam.

Let $\Delta \varepsilon_{u}$ and $\Delta \varepsilon_{l}$ be defined as the increment of the strains on the upper and lower flanges respectively, $\Delta \varepsilon_{m}$ be the increment of the average axial strain, and $\Delta \phi$ express the increment of the curvature.

By using symbols as shown in Fig.19, the formulae

$$
\left\{\begin{array}{l}
\Delta \varepsilon_{u}=\Delta \varepsilon_{m}+\Delta \phi \frac{D}{2} \\
\Delta \varepsilon_{l}=\Delta \varepsilon_{m}-\Delta \phi \frac{D}{2}
\end{array}\right.
$$

hold. Letting $\Delta \sigma_{u}$ and $\Delta \sigma_{l}$ be the increments of the stress on the upper and lower flanges respectively, the relations

$$
\left\{\begin{array}{l}
\Delta \sigma_{u}=E_{f u} \Delta \varepsilon_{u} \\
\Delta \sigma_{l}=E_{f l} \Delta \varepsilon_{l}
\end{array}\right.
$$

are defined to hold, where $E_{f u}$ and $E_{f l}$ respectively mean the Young's modulus of the upper and lower flanges in the infinitesimal section.

Hence, the increment of the axial force $\Delta P$ is expressed by the following formula :

$$
\Delta P=\Delta \sigma_{u} B t+\Delta \sigma_{l} B t
$$

By substituting Eqs.(22) and (23) into the above expression,

$$
\Delta P=\left(E_{f u}-E_{f l}\right) B t \frac{D}{2} \Delta \phi+\left(E_{f u}+E_{f l}\right) B t \Delta \varepsilon_{m}
$$

is derived. Because the axial force is constant in this analysis,

$$
\Delta P=0
$$

must hold as a condition. By putting the above expression (26) into Eq.(25), the average axial strain $\Delta \varepsilon_{m}$ is expressed in the following formula :

$$
\Delta \varepsilon_{m}=-\frac{E_{f u}-E_{f l}}{E_{f l}+E_{f u}} \frac{D}{2} \Delta \phi
$$

If the value of $\Delta \varepsilon_{m}$ is found, it follows that the increments $\Delta \varepsilon_{u}$ and $\Delta \varepsilon_{l}$ are determined with Eq. (22). However, since $E_{f u}$ and $E_{f l}$ are unknown in Eq.(27), the value of $\Delta \varepsilon_{m}$ can not be determined even if the value of $\Delta \phi$ is known. Accordingly, in this analysis, the value of $\Delta \varepsilon_{m}$ at the former stage is used as the first approximate value considering that the value of $\Delta \varepsilon_{m}$ is infinitesimal. Namely, $\Delta \varepsilon_{u}$ and $\Delta \varepsilon_{l}$ are found by substituting the first approximate value $\Delta \varepsilon_{m}$ into Eq.(22), and then $\Delta \varepsilon_{u}$ and $\Delta \varepsilon_{l}$ are determined with aid of the fuzzy constitutive relation. If the values of $\Delta \varepsilon_{u}, \Delta \varepsilon_{l}, \Delta \sigma_{u}$ and $\Delta \sigma_{l}$ corresponding to the first approximate values are found, the values of $E_{f u}$ and $E_{f l}$ are found by substituting each value into Eq.(23). If $E_{f u}$ and $E_{f l}$ are put into Eq.(27) once more, the second approximate value of $\Delta \varepsilon_{m}$ is obtained. After repeating such a procedure in several times, the increment of the axial force $\Delta P$ converges into zero.

Using the last values of $\Delta \varepsilon_{u}$ and $\Delta \varepsilon_{l}$ determined by the above-mentioned procedure, the increment of the bending moment $\Delta M$ is determined by the following expression :

$$
\begin{aligned}
\Delta M & =\Delta \sigma_{u} B t \frac{D}{2}-\Delta \sigma_{l} B t \frac{D}{2} \\
& =\left(E_{f u}+E_{f l}\right) B t \frac{D^{2}}{4} \Delta \phi+\left(E_{f u}-E_{f l}\right) B t \frac{D}{2} \Delta \varepsilon_{m} \\
& =\frac{E_{f u} E_{f l}}{E_{f u}+E_{f l}} B t D^{2} \Delta \phi
\end{aligned}
$$

\section{(3) Elastic Web Model}

Fig.20 shows Elastic Web Model. In this second model, the resistance of web elements is taken into account on condition that the web elements always behave elastically and yield no local buckling, that is to say, the deterioration of stress does not occur in the web plates.

The basic algorithm follows the case of the Double flange model, and yet Eq.(25) is changed as follows, taking the elastic behavior of web plates into consideration.

$$
\begin{aligned}
\Delta P= & \left(E_{f u}-E_{f l}\right) B t \frac{D}{2} \Delta \phi \\
& +\left\{\left(E_{f u}+E_{f l}\right) B t+2 D t E_{w}\right\} \Delta \varepsilon_{m}
\end{aligned}
$$

Hence, by substituting Eq.(26) into Eq.(29), $\Delta \varepsilon_{m}$ in the Elastic Web Model is expressed by the following expression : 

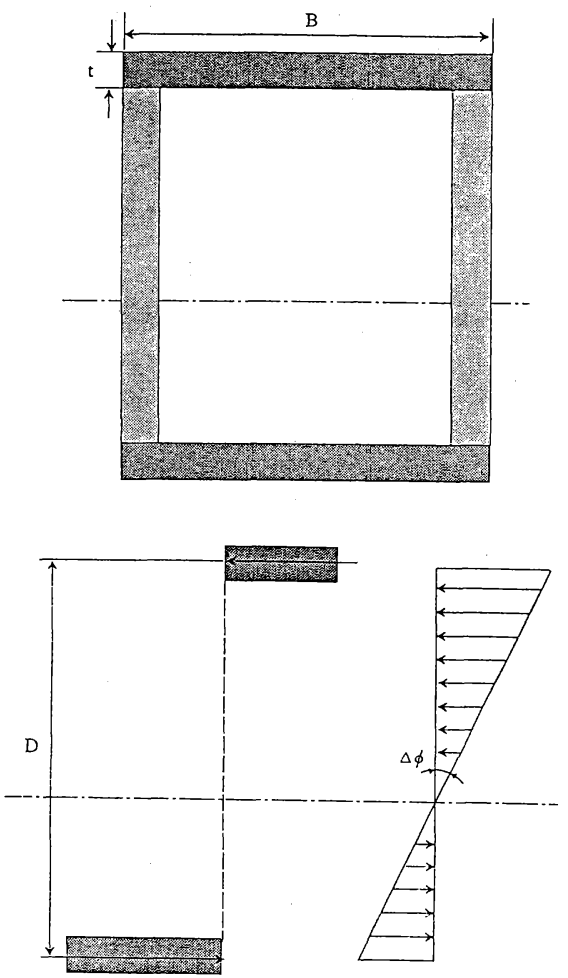

Fig.20 Elastic web model

$$
\Delta \varepsilon_{m}=-\frac{\left(E_{f u}-E_{f l}\right) B t \frac{D}{2} \Delta \phi}{\left(E_{f u}+E_{f l}\right) B t+2 D t E_{w}}
$$

Besides, letting $\Delta M_{f}$ and $\Delta M_{w}$ be the increments of the bending moment shared by the flanges and web plates respectively,

$$
\begin{gathered}
\Delta M_{f}=\left(E_{f u} \frac{\Delta \varepsilon_{u}^{2}}{\Delta \varepsilon_{u}-\Delta \varepsilon_{l}}+E_{f l} \frac{\Delta \varepsilon_{l}^{2}}{\Delta \varepsilon_{u}-\Delta \varepsilon_{l}}\right) B t D \\
\Delta M_{w}=\frac{4}{3} E_{w} \frac{\Delta \varepsilon_{u}^{2}+\Delta \varepsilon_{u} \Delta \varepsilon_{l}+\Delta \varepsilon_{l}^{2}}{\Delta \varepsilon_{u}-\Delta \varepsilon_{l}} D^{2} t
\end{gathered}
$$

hold, and the value of the general bending moment is given by the following expression :

$$
\Delta M=\Delta M_{f}+\Delta M_{w}
$$

\section{(4) Elastoplastic Web Model}

In the case of the Elastic Web Model, the web plates have been assumed to be elastic body, while the elastoplastic behavior is taken into consideration by use of a yield surface in the Elastoplastic Web Model. Accordingly, it may be said that the more realistic behavior of the web plates than the Elastic Web Model can be expressed by introducing the formula of the yield surface. The yield surface assumed in the Elastoplastic Web Model is shown in Fig.21.

Eq.(34) expresses the limit state of the yield

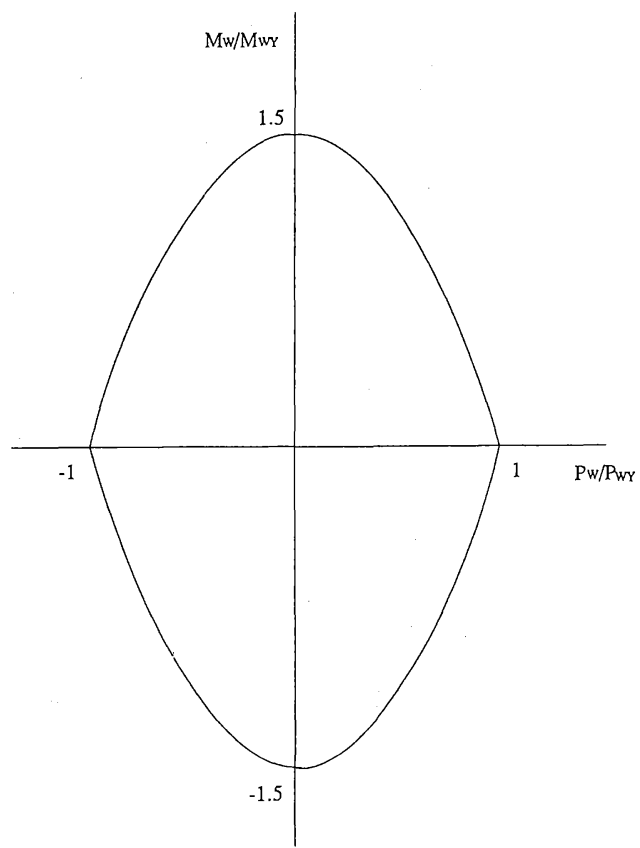

Fig.21 Yield surface of elastoplastic web model

surface $^{25)}$

$$
\frac{2}{3}\left|\frac{M_{w}}{M_{w y}}\right|+\left(\frac{P_{w}}{P_{w y}}\right)^{2}=1
$$

where $M_{w y}$ and $P_{w y}$ express the yield moment of the web and the yield axial force, respectively.

Another yield surface such as a square surface is used in calculation as a trial, but it is verified that the yield surface expressed in Eq.(34) causes more precise results.

The fundamental procedure of the analysis is the same as that of the Elastic Web Model, and yet it is considered that the web plates behave elastically when the load is within the domain of the yield surface. Therefore, $\Delta \varepsilon_{m}, \Delta M_{f}$ and $\Delta M_{w}$ are as follows.

In the domain :

$$
\begin{gathered}
\Delta \varepsilon_{m}=-\frac{\left(E_{f u}-E_{f l}\right) B t \frac{D}{2} \Delta \phi}{\left(E_{f u}+E_{f l}\right) B t+2 D t E_{w}} \\
\Delta M_{f}=\left(E_{f u} \frac{\Delta \varepsilon_{u}^{2}}{\Delta \varepsilon_{u}-\Delta \varepsilon_{l}}+E_{f l} \frac{\Delta \varepsilon_{l}^{2}}{\Delta \varepsilon_{u}-\Delta \varepsilon_{l}}\right) B t D \\
\Delta M_{w}=\frac{4}{3} E_{w} \frac{\Delta \varepsilon_{u}^{2}+\Delta \varepsilon_{u} \Delta \varepsilon_{l}+\Delta \varepsilon_{l}^{2}}{\Delta \varepsilon_{u}-\Delta \varepsilon_{l}}
\end{gathered}
$$

Out of the domain :

$$
\begin{gathered}
\Delta \varepsilon_{m}=-\frac{E_{f u}-E_{f l}}{E_{f l}+E_{f u}} \frac{D}{2} \Delta \phi \\
\Delta M_{f}=\left(E_{f u} \frac{\Delta \varepsilon_{u}^{2}}{\Delta \varepsilon_{u}-\Delta \varepsilon_{l}}+E_{f l} \frac{\Delta \varepsilon_{l}^{2}}{\Delta \varepsilon_{u}-\Delta \varepsilon_{l}}\right) B t D
\end{gathered}
$$


Table 4 Design measurements of specimens SC and SD

\begin{tabular}{|c|c|c|c|c|c|c|c|}
\hline SPECIMEN & $\begin{array}{c}\text { FLANGE } \\
\mathrm{B}(\mathrm{mm})\end{array}$ & $\begin{array}{c}\text { WEB } \\
\mathrm{D}(\mathrm{mm})\end{array}$ & $\begin{array}{c}\text { CORNER } \\
\mathrm{r}(\mathrm{mm})\end{array}$ & $\begin{array}{c}\text { THICKNESS } \\
\mathrm{t}(\mathrm{mm})\end{array}$ & $\begin{array}{c}\text { LENGTH } \\
\mathrm{L}(\mathrm{mm})\end{array}$ & $\begin{array}{c}\text { AREA } \\
\left.\text { A ( } \mathrm{cm})^{2}\right)\end{array}$ & $\begin{array}{c}\text { MOMENT } \\
\left.\text { INERTIA I ( }{ }^{4}\right)\end{array}$ \\
\hline SC-type & 250.0 & 300.0 & - & 4.5 & 600.0 & 49.5 & 6937.1 \\
\hline SD - type & 159.0 & 200.0 & 50.0 & 4.5 & 600.0 & 45.8 & 6049.9 \\
\hline
\end{tabular}

Table 5 Yield points and width-thickness ratios $\mathbf{R}$

\begin{tabular}{|c|c|c|c|c|}
\hline \multirow{2}{*}{ SPECIMEN } & \multirow{2}{*}{$\begin{array}{c}\text { Py } \\
\text { (tonf })\end{array}$} & \multicolumn{3}{|c|}{ Generalized Width-Thickness Ratio R } \\
\cline { 3 - 5 } & & Plate & Web & Corner \\
\hline SC-Type & 118.8 & 1.01 & 1.17 & - \\
\hline SD-Type & 109.9 & 0.63 & 0.79 & 0.14 \\
\hline
\end{tabular}

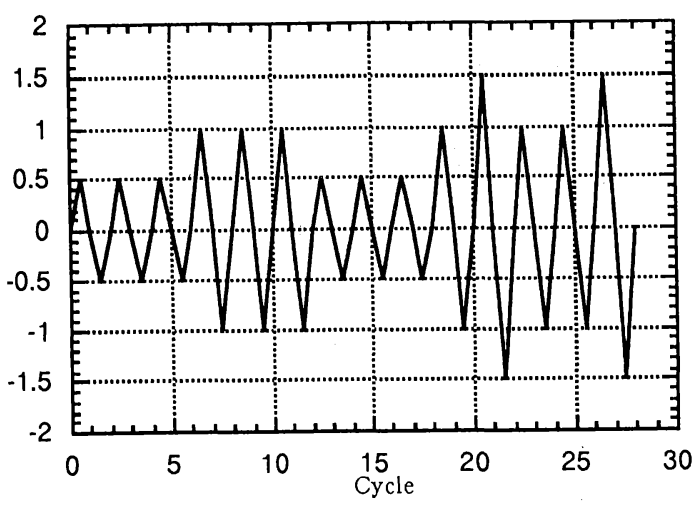

Fig.22 Loading pattern to SC

$$
\Delta M_{w}=0
$$

Consequently, the increment of the general bending moment is obtained from Eq.(33).

\section{COMPARISON BETWEEN RESULTS BY ANALYTICAL MODEL BASED ON FUZZY CONSTITUTIVE RELA- TION AND EXPERIMENTAL RE- SULTS}

\section{(1) Outline}

In this chapter, the analytical results by the models described in the former chapter are compared with the experimental results obtained from bending tests. And the validity of the analytical models is examined ${ }^{14), 20) 24}$. The objects in this analysis are Specimen C (SC type) with a rectangular section and a round-cornered box type Specimen D (SD type), which have been used for

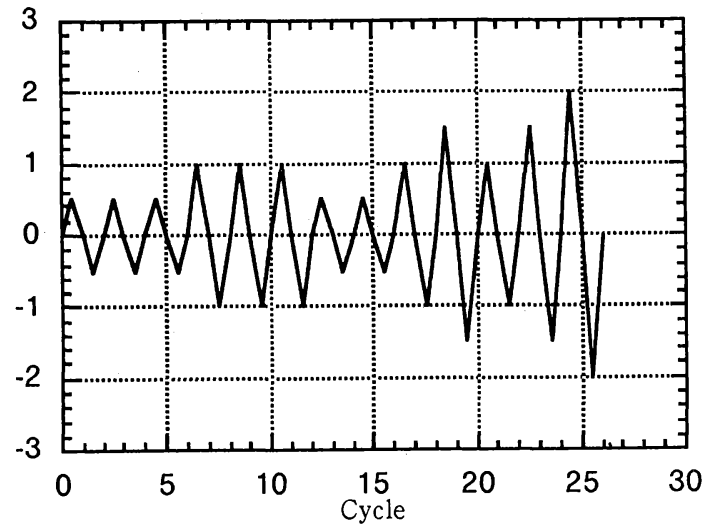

Fig.23 Loading pattern to SD

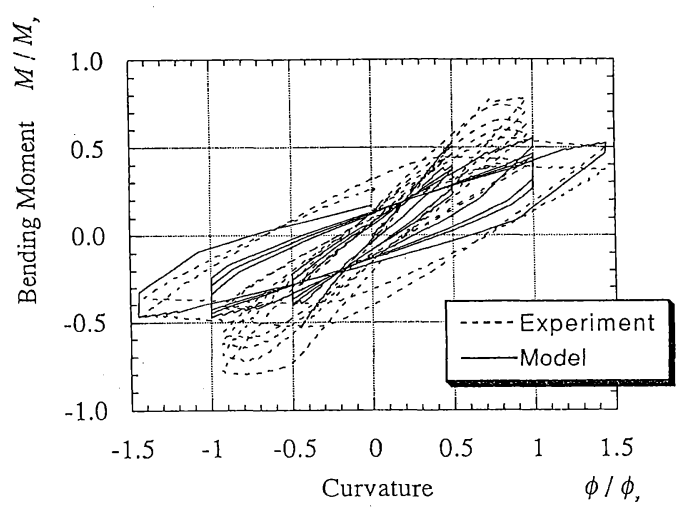

Fig.24 Result by double flange model (SC)

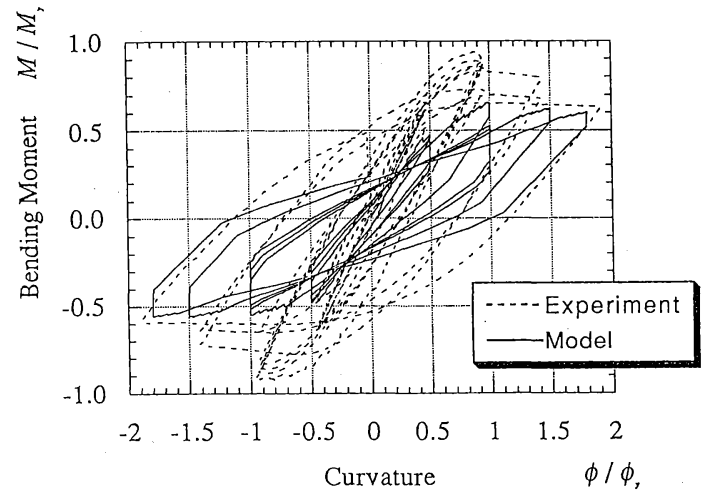

Fig.25 Result by double flange model (SD) 


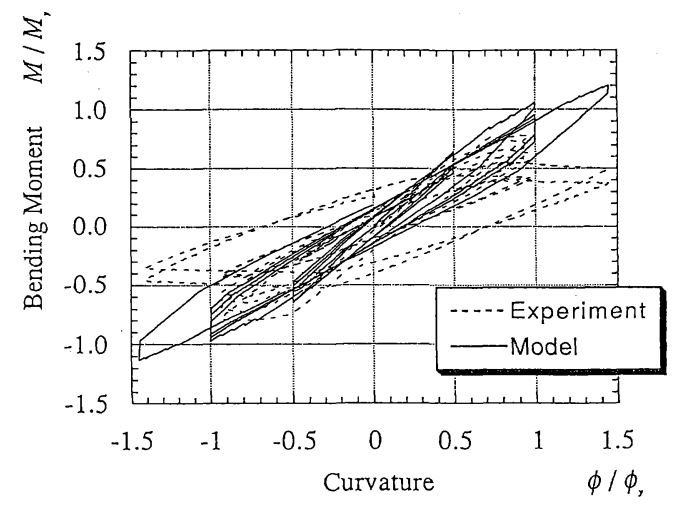

Fig.26 Result by clastic web model (SC)

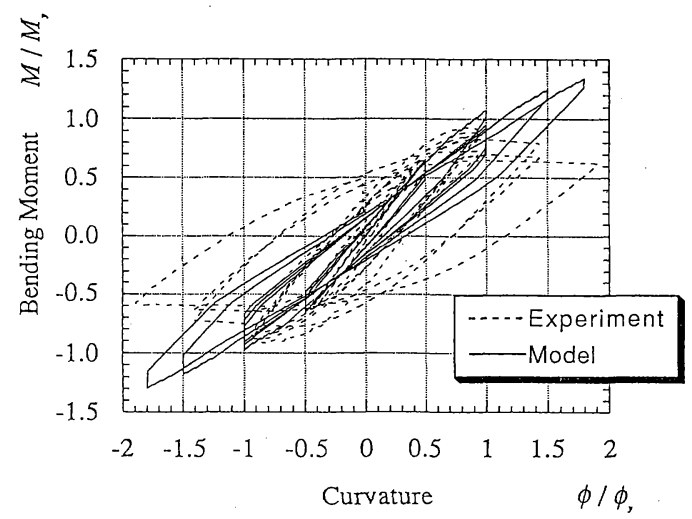

Fig.27 Result by elastic web model (SD)

the bending test. The design measurements of the specimens SC and SD are tabulated in Table 4. The yield points and the generalized width-thickness ratios are shown in Table 5. And the loading patterns to SC and SD are shown in Figs.22 and 23 respectively.

\section{( 2 ) Results by Double Flange Model}

The results analyzed by the Double Flange Model are shown in Figs.24 and 25.

Comparing the analytical results with experimental results, the peaks of strength are low, especially in the early stage of the loading cycle. In the experimental results, the largest peak of the strength occurs earlier, while in the analytical results, the strength rises slowly, and the largest peak of the strength occurs late.

From what is mentioned above, the analysis by the Double Flange Model is inappropriate. Because the strength of the web plates is not considered, the general strength is evaluated low in this model.

\section{( 3 ) Results by Elastic Web Model}

The results by the Elastic Web Model are shown

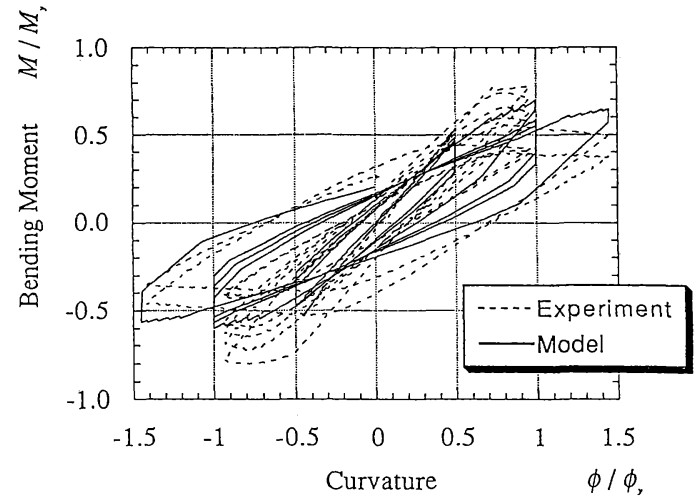

Fig.28 Result by elastoplastic web model (SC)

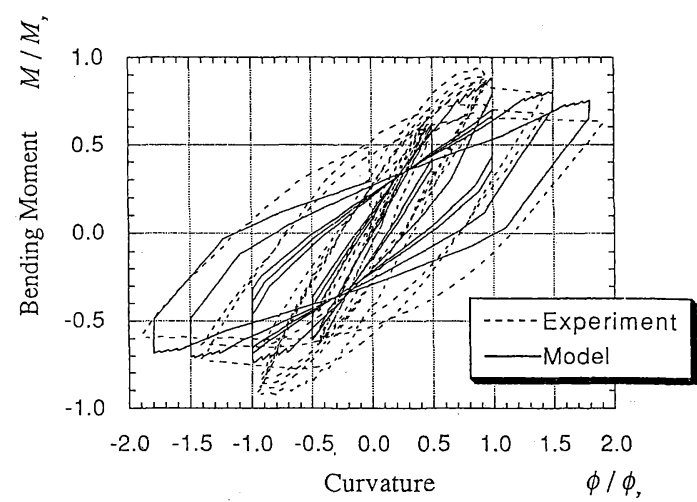

Fig.29 Result by elastoplastic web model (SD)

in Figs.26 and 27. Since the web plates are always regarded as an elastic body, the deterioration of the strength of the web never occurs. Accordingly it is obvious that the more absolute value of the curvature increases, the more the strength of the web always increases continuously. It is considered that this implies that because the degree of rise of the web strength is more eminent than that of decline of the flange strength after the flanges have attained the peak strength, the general strength rises at all times.

Consequently, in the case that the web plates are assumed to be an elastic body, the model can not represent the behavior after the flanges have reached the peak strength. That is why the Elastic Web Model is not appropriate for the evaluation of restoring characteristics concerned with a section of the thin-walled composite segments.

\section{(4) Results by Elastoplastic Web Model}

The results by the Elastoplastic Web Model are shown in Figs.28 and 29.

The analytical result for SC is shown in Fig.28 and the one for SD is shown in Fig.29. From these 
results, the analytical consequence by Elastoplastic Web Model corresponds more precisely to the experimental results comparing with Double Flange Model and Elastic Web Model.

From what is stated above, the modelling based on the fuzzy reasoning with the five fuzzy inference rules and its application to the prediction of the cyclic behavior concerned with a section of the thin-walled hollow segments can be said to be a certain degree of success in the case that Elastoplastic Web Model is used. But in also the Elastoplastic Web Model, it can not be said that the analytical model estimates the cyclic behavior very well. Accordingly, the modelling method should be continuously improved from now on.

\section{CONCLUDING REMARKS}

Although the fuzzy theorem, in this study, is used to make the modelling of the constitutive relation, the relation between the fuzziness and the human subjectivity is not distinct very well. The intention using the fuzzy reasoning lies in making the definition of the relation between the fuzziness and the human subjectivity conducted easily in the future.

In this research, the tuning method has been formulated to express the arbitrary curves with the fuzzy inference rules and the efficiency and the applicability of the method have been demonstrated through several numerical calculations. The method to represent the arbitrary curves based on the fuzzy reasoning has been applied to the modelling of the hysteretic curves on the simple plate element under the repetitive compressivetensile load. Using this method, the so-called "Fuzzy Constitutive Relation" has been derived. Then, the Fuzzy Constitutive Relation has been applied to the prediction of the cyclic behavior concerned with a section of the thin-walled hollow segments under the constant compressive thrust and the repetitive bending.

Consequently, the following conclusions are derived :

a) The validity of the identification method based on the successive learning of the rule parameters has been verified. And the various shapes of curves can be expressed by the fuzzy inference rules even if the number of the rules is rather few as five. b) The complex and nonlinear hysteretic curves of the simple plate element can be represented with Fuzzy Constitutive Relation defined by the fuzzy inference rules.

c) The Fuzzy Constitutive Relation can introduce the knowledge and the insight of engineers into the formulation. Through the qualitative interpretation of the parameters involved in the inference rules, it is possible to easily consider the difference of material characteristics in establishing the constitutive model. In the analysis of the thin-walled hollow segments subjected to the constant thrust and the repetitive bending, the cyclic behavior concerned with a section of the segments can be predicted by Elastoplastic Web Model with a certain degree of success comparing with Double Flange Model and Elastic Web Model.

Fuzzy Constitutive Relation Model works in the above three analytical models. If the experimental data can be sufficiently collected, the constitutive model can be improved through the learning process. It can be said that the proposed model, i.e., the Fuzzy Constitutive Relation Model, lies between the ordinal analytical model based on physical characteristics and the model based on the Neural Network. Although the Neural Network Model is superior to interpolate experimental data, it is difficult to show a logical base to reach the final result. On the contrary, the proposed method can provide us both the interpretation of the parameters and the satisfactory accuracy gained by the learning ability.

Relating the dynamic parameters with the parameters described in this study should be continuously carried out from now on. As an another strategy in future, it can be considered that first the modelling of a skeleton curve is made, and then the modelling of the constitutive relation based on the fuzzy reasoning is developed under the repetitive loading.

\section{REFERENCES}

1) Yao, T. and Nikolov, P.I. : Numerical experiment on buckling/plastic collapse behavior of plates under cyclic loading, Stability and Ductility of Steel Structures under Cyclic Loading, CRC Press, Inc., pp.203-224, 1992.

2) Fukumoto, Y. and Kusama, H. : Cyclic bending tests of thin-walled box beams, Proc. of JSCE Structural Eng./Earthquake Eng., Vol.2, No.1, pp.141-151, Apr. 1985.

3) Furuta, H. : Fuzzy, its basis and application (the Former), Highway and Motorcar, Vol.4, Number 34, Apr., 1991. (in Japanese)

4) Ezawa, Y. and Kandel, A. : Robust fuzzy inference, International Journal of Intelligent Systems, Vol.6, pp.185197, 1991.

5) Yamada, T. and Suzuki, K. : Fuzzy control of plural hydraulic jacks in an elastic-plastic structural test, Proc. of IEEE International Conference on Fuzzy Systems, pp.546$551,1990$.

6) Ichihashi, H. : Fuzzy reasoning and expert system, Proc. of 2 nd Workshop-Knowledge acquisition and learning in the fuzzy theory-, pp.1-6, Jan., 1991. (in Japanese) 
7) Nomura, H., Hayashi, I. and Wakami, N. : Self-tuning methód of fuzzy reasoning by Hopfield Neural Network, Proc. of 5 th Fuzzy System Symposium, pp.177-182, Jun., 1989.

8) Minami, M., Watanabe, E. and Furuta, H. : Application of fuzzy theory for vibration control of offshore structures, Graduation Thesis, Kyoto Univ., Feb., 1992. (in Japanese)

9) Nomura, H., Hayashi, I. and Wakami, N. : A learning method of fuzzy inference rules by descent method, Proc. of IEEE. International Conference on Fuzzy Systems, pp.203-210, Mar., 1992.

10) Ichihashi, H. : Back propagation error learning with hierarchical fuzzy models-Online GMDH algorithmsProc. of 6 th Fuzzy System Symposium, pp.539-542, Sep., 1990. (in Japanese)

11) Nomura, H., Hayashi, I. and Wakami, N. : A Self tuning method of fuzzy reasoning by method of steepest descent and its application to moving obstacle avoidance, Proc. of 6 th Fuzzy System Symposium, pp.423-426, Sep., 1990. (in Japanese)

12) Watanabe, T. and Ichihashi, H. : Fuzzy control of a robotic manipulator learning inverse kinematics and dynamics models, Proc. of 6 th Fuzzy System Symposium, pp.185197, Sep. 6-8, 1990. (in Japanese)

13) Ichihashi, H. : Hierarchical fuzzy model of class $C$, Proc. of 7 th Fuzzy System Symposium, pp.505-508, Jun., 1991. (in Japanese)

14) Ichihashi, H. : Neuro-fuzzy finite element method and system optimization, Proc. of 8 th Fuzzy System Symposium, pp.213-216, 1992.

15) Ohsato, A. and Sugeno, M. : Identification of ill-defined systems by means of convexly combined fuzzy relational equations, Proc. of 3 th Fuzzy System Symposium, pp. 8994, Jun., 1987. (in Japanese)

16) Ohsato, A. and Sekiguchi, T. : Function representation using fuzzy inference, Proc. of 5 th Fuzzy System Symposium, pp.467-472, Jun., 1989. (in Japanese)
17) Kosko, B. : Fuzzy systems as universal approximators, Proc. of IEEE International Conference on Fuzzy Systems, pp.1153-1162, Mar., 1992.

18) Mori, T. : Simplified analytical method on hysteretic behavior of thin-walled box members under repetitive load, Master Thesis, Kyoto Univ., Feb., 1991. (in Japanese)

19) Watanabe, E., Sugiura, K., Mori, T. and Suzuki, I. : Modelling of hysteretic behavior of thin-walled box members, Stability and Ductility of Steel Structures under Cyclic Loading, CRC Press, Inc., pp.225-235, 1992.

20) Watanabe, E., Kitazawa, M. and Okuno, M. : Simplified analysis on load distribution of steel box beam-columns, Journal of Structural Engineering, Vol. 34 A, pp.233-242, Mar., 1988. (in Japanese)

21) Sugiura, K. and Watanabe, E. : Modelling of inelastically sectional behavior of beam-column segment, Journal of Numerical Analysis Symposium in Structural Engineering, Vol.13, pp.365-370, Jul., 1989. (in Japanese)

22) Nonaka, T. : Closed-form formulation for the hysteretic behavior of a bar under repeated axial loading, Part 1, Derivation of basic equations, Transaction of Architectural Institute of Japan, Num. 334, pp.1-7, Dec., 1983. (in Japanese)

23) Nonaka, T. : Closed-form formulation for the hysteretic behavior of a bar under repeated axial loading, Part 3, Plastic hysteretic characteristics, Transaction of Architectural Institute of Japan, Number 343, pp.42-50, Sep., 1984. (in Japanese)

24) Yamamoto, K. : Modelling of hysteretic behavior with neural networks and its application to non-linear dynamic analysis, Journal of Structural Engineering, Vol.38 A, pp.85-94, Mar., 1992. (in Japanese)

25) Chen, W. F. and Atsuta, T. : Theory of Beam-Columns, Vol.2, McGraw-Hill, Inc., pp.282-291, 1977.

(Received June 8, 1994)

\title{
ファジィ推論に基づく構成則を用いた弾塑性解析
}

\author{
熊崎幾太郎・渡邊英一・古田 均
}

本論文では, ファジィ推論ルールの前件部および後件部パラメータを最急勾配法により学習同定する手法を用 いて，ファジィ推論に基づく構成則を得る．学習同定には，橋脚の柱セグメントを構成する単一板に関する繰返 し圧縮・引張実験データを用いる．この構成則を橋脚の柱セグメントである薄板集成部材が一定圧縮荷重および 繰返し曲げを受ける場合の部材断面レベルでの弾塑性挙動予測に応用する. 